\title{
Earthworms in Short-Term Contact with a Low Dose of Neonicotinoid Actara 25WG
}

\author{
Mariola Garczyńska1*, Grzegorz Pączka', Anna Mazur-Pączka', Joanna Kostecka' \\ ${ }^{1}$ Department of Natural Theories of Agriculture and Environmental Education, Faculty of Biology and \\ Agriculture, University of Rzeszów, 35-601 Rzeszów, ul. Ćwiklińskiej 2, Poland \\ * Corresponding author's e-mail: mgar@ur.edu.pl
}

\begin{abstract}
A laboratory experiment, carried out for five months, was designed to assess the effects produced by the neonicotinoid Actara $25 \mathrm{WG}$, used at a dose recommended by the manufacturer, in the dynamics of the populations of epigeic Eisenia fetida (Sav.) and Dendrobena veneta (Rosa)earthworms. The study was conducted in a climatic chamber and involved balanced biomass of mature specimens representing both species, in 3 replications of soil medium with the insecticide, in addition to controls. The growing populations were inspected five times, by means of manual segregation of the substrate. The insecticide led to an increase in both the number of specimens and the biomass of E. fetida population (overall, as well as mature and immature worms), yet it reduced their reproduction (decreased the number of cocoons) $(\mathrm{p}<0.05)$. In the case of D.veneta, the neonicotinoid insecticide produced positive effects only in the mature specimens $(\mathrm{p}<0.05)$.
\end{abstract}

Keywords: worms, Eisenia fetida (Sav.), Dendrobena veneta (Rosa), neonicotinoids, Actara 25 WG

\section{INTRODUCTION}

Due to the industrialization of agriculture and excessive use of chemicals, more and more toxic xenobiotics find their way into the natural environment. Approximately 13 million chemical compounds are already known and about 100,000 of these are manufactured in large quantities. The use of many of the chemicals leads to serious deterioration of the soil quality, partly resulting from the hazards towards the soil fauna. The latter must cope with xenobiotics and complex residues from their synergistic and antagonistic reactions (Walker et al. 2002; Laskowski \& Migula 2004).

Chemical substances such as neonicotinoids are commonly used. It is estimated that this group of xenobiotics accounts for approximately $1 / 4$ of all the insecticides manufactured globally (Jeschke et al. 2010, 2013; Wang et al. 2015a, b). They are widely used to eliminate harmful insects feeding on crops (e.g. sucking and chewing insects, such as whiteflies, thrips, aphids, certain microlepidoptera and beetles). Irrespective of the way they are absorbed by plants, neonicotinoids have a capacity to translocate to all parts of the organism. Therefore, they are able to control a large spectrum of pest insects (Simon-Delso et al. 2015).

Because of the wide range of systemic and translaminar effects and their unique activity, neonicotinoids rank among the most popular groups of insecticides. Yet, numerous researchers point out their negative influence on the functioning of ecosystems. This is partly associated with the non-target effects observed in the populations of pollinators (bees, bumblebees) and insectivorous birds. In the areas where these insecticides are used, related contaminations were identified in pollen range from 11 to $24 \%$ and in nectar from 17 to $65 \%$ (Kreutzweiser et al. 2009; Gill et al. 2012; Whitehorn et al. 2012; Hallman et al. 2014; Sánchez-Bayo \& Hyne 2014). With respect to the colony collapse disorder in 2013, the European Food Safety Authority restricted the use of three most hazardous neonicotinoid insecticides: imidacloprid, thiamethoxam and clothianidin (European Commission 2013). 
Many studies suggest that even if they are used in the doses defined by their manufacturers as 'safe for the environment', xenobiotics are likely to affect numerous soil organisms, and consequences of their application cannot be predicted with sufficient certainty (Garczyńska \& Kostecka 2011a,b, 2012; Jovana et al. 2014; Krüpke \& Long 2015; Uhl et al. 2015).

The experiment described here was designed to assess the effects of the insecticide Actara $25 \mathrm{WG}$, on two species of earthworms.

\section{MATERIAL AND METHODS}

\section{Earthworms}

The experiment used earthworms (Oligochaeta; Lumbricidae) from breeding stocks at the University of Rzeszów's Department of Natural Theories of Agriculture and Environmental Education. The experiment was designed to investigate two species: Eisenia fetida (Savigny 1826) and Dendrobena veneta (Rosa 1893), which were previously acclimatized in potting soil.

\section{Formulation applied}

Actara 25WG (Syngenta Crop Protection $A G)$ is a neonicotinoid insecticide, where the active ingredient is thiamethoxam: 3-(2-chloro-1,3-thiazol-5-ylmethyl)-5-methyl-1,3,5-oxadiazinan-4-ylidene(nitro)amine. The formulation was applied once, at a dose recommended by the manufacturer (as an equivalent concentration of $\left.0.003 \mathrm{mg} \cdot \mathrm{dm}^{-3}\right)$.

\section{Experimental procedure}

The study investigated balanced biomass of mature specimens of E. fetida and D. veneta. All specimens had a well-developed clitellum. Plastic containers $(20 \times 15 \times 10 \mathrm{~cm})$ were filled with potting soil and then 20 E. fetida or $10 \mathrm{D}$. veneta were placed in each of them (Table 1). In order to reduce the growth of potworms, competing with earthworms, kitchen waste subjected to vermicomposting was mixed with cellulose (in the ratio 2:1) (Kostecka 2000). The waste was supplied regularly, and placed in $5 \mathrm{~mm}$ mesh nylon net.

The experiment was conducted for 5 months (from December 2015 to May 2016). Every month the condition of the growing population of earthworms was inspected through the use of manual segregation of substrate (e.g. Pelosi et al. 2009). The experiment was carried out in a climatic chamber $\left(20 \pm 5^{\circ} \mathrm{C}, 24 \mathrm{~L}\right.$; at soil moisture of approx. 70\%) (OECD 1984, 2004).

\section{Statistical analysis}

The findings are presented in the form of arithmetic means and standard deviations (SD). The statistical calculations were performed with the use of STATISTICA software v. 10 (StatSoft). Normal distribution was examined with ShapiroWilk $W$-test and Brown Forsythe test for verifying homogeneity of variances. Statistical significance was determined with Student's t-test a (Stanisz 2006). The significance of differences was assumed at $\alpha=0.05$.

\section{RESULTS}

\section{Effects of insecticide Actara 25WG in E.fetida earthworms}

The findings suggest positive effects of $A c$ tara $25 W G$ (applied at the manufacturer's recommended dosage), in both the size and the biomass of mean population of E. fetida (mature and immature specimens) (size $\mathrm{t}=5.362, \mathrm{p}<0.05$; biomass $\mathrm{t}=32.47, \mathrm{p}<0.001$ ) (Fig. 1).

The study also identified the positive effects of Actara $25 W G$ on the size and biomass of mature specimens of this species. The containers with the formulation were found to contain significantly more mature specimens, compared to the control (Actara $-153 \pm 20$ spec. cont. $^{-1}$; control $-105 \pm 9$ spec. cont. $\left.^{-1} ; \mathrm{t}=3.795, \mathrm{p}<0.05\right)$. The xenobiotic also significantly stimulated the growth of their mean biomass (Actara $-70.745 \pm 0.763 \mathrm{~g} \cdot$ cont. $^{-1}$;

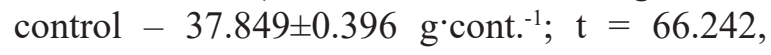
$\mathrm{p}<0.001$ ) (Fig. 2).

The positive response to the formulation of immature specimens was only observed in their number. Five months after the xenobiotic was applied, the boxes with the insecticide were found to contain $57 \pm 9$ spec. cont. $^{-1}$, compared to the controls amounting to $32 \pm 2$ spec. cont. $^{-1}(\mathrm{t}=4.6433$, $\mathrm{p}<0.01)$. No differences were identified in the mean biomass of immature specimens $(p>0.05)$ (Table 2).

The presence of the insecticide reduced the number of cocoons produced by earthworms $(t=3.9043, p<0.05)$ without differentiating their biomass ( $\mathrm{p}>0.05$ ) (Fig. 3). 
Table 1. Experimental procedure

\begin{tabular}{|c|c|c|c|c|}
\hline \multirow{2}{*}{ Containers } & \multirow{2}{*}{ Substrate } & \multicolumn{2}{|c|}{ Earthworms } & \multirow{2}{*}{ Waste subjected to vermicomposting } \\
\hline & & E. fetida & D.veneta & \\
\hline $\begin{array}{c}1-3 \\
\text { control }\end{array}$ & \multirow{2}{*}{$\begin{array}{l}\text { each } 1.5 \mathrm{dm}^{3} \text { of } \\
\text { potting soil }\end{array}$} & \multirow{2}{*}{$\begin{array}{l}20 \text { specimens in } \\
\text { each container* } \\
\quad(7.52 \pm 0.04)\end{array}$} & \multirow{2}{*}{$\begin{array}{l}10 \text { specimens in } \\
\text { each container } \\
(7.54 \pm 0.04)\end{array}$} & \multirow{2}{*}{$\begin{array}{l}\text { supplied } 5 \text { times, each } 600 \mathrm{ml} \text { of kitchen } \\
\text { waste mixed with } 300 \mathrm{ml} \text { of cellulose**** }\end{array}$} \\
\hline $\begin{array}{c}4-6 \\
\text { formulation* }\end{array}$ & & & & \\
\hline
\end{tabular}

* formulation Actara25WG equivalent to the dose of $0.003 \mathrm{mg} \cdot \mathrm{dm}^{-3}-$ in accordance with the manufacturer's recommendations

** all-purpose Kronen soil: $\mathrm{pH}$ in $\mathrm{H}_{2} \mathrm{O}$ 6.0-6.5; salinity 1.0-2.0 $\left(\mathrm{mg} \cdot \mathrm{dm}^{-3}\right) ; \mathrm{N} 200-450\left(\mathrm{mg}^{-\mathrm{dm}^{-3}}\right) ; \mathrm{P}_{2} \mathrm{O}_{5} 200-400$ $\left(\mathrm{mg} \cdot \mathrm{dm}^{-3}\right) ; \mathrm{K}_{2} \mathrm{O} 300-500\left(\mathrm{mg} \cdot \mathrm{dm}^{-3}\right)$; solid form, loose, fraction 0-20 mm

*** known and balanced biomass within each container

$* * * *$ waste of pasta, bread, as well as apple and potato peelings, at the rate 1:1:1:1

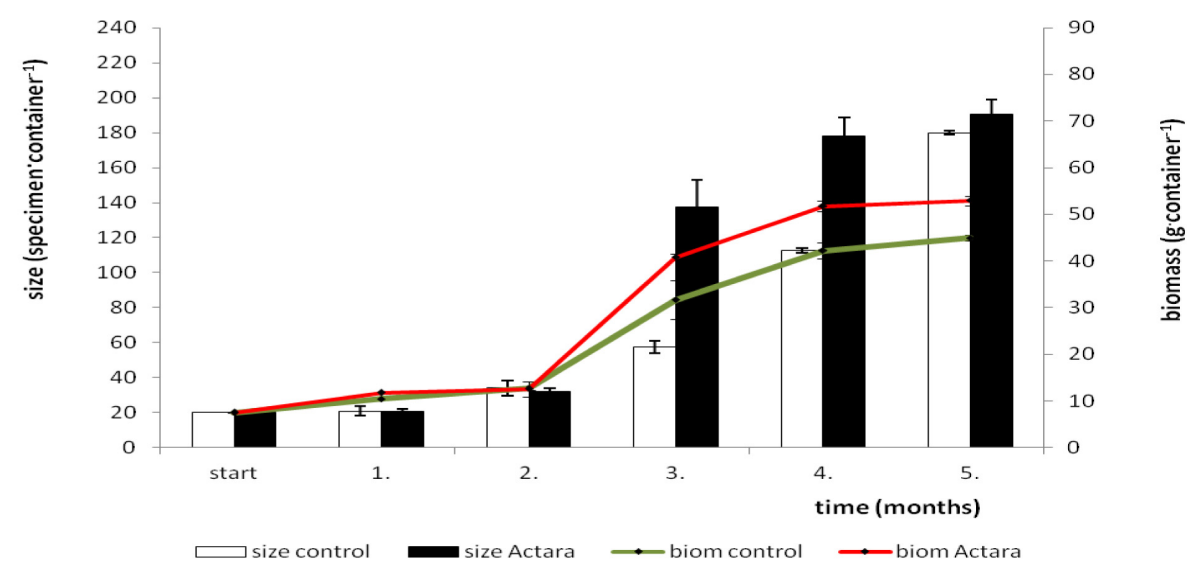

Figure 1. Effects of the xenobiotic Actara $25 W G$ in the dynamics of size and biomass of mean population of earthworm E. fetida

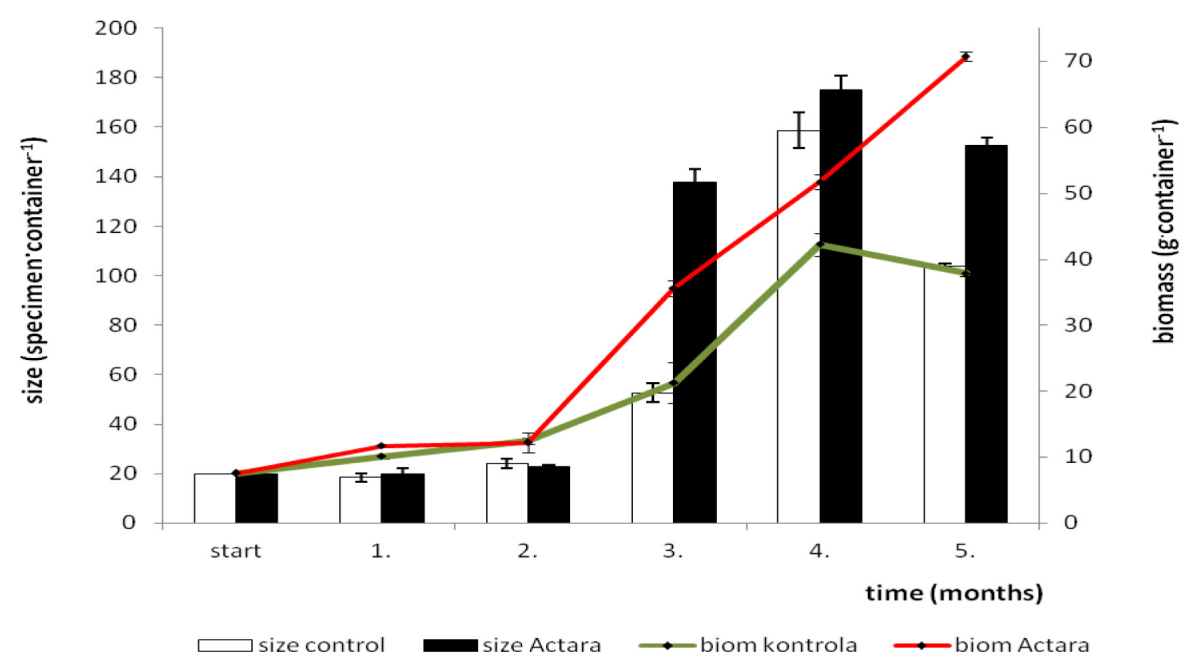

Figure 2. Effects of the xenobiotic Actara $25 W G$ in the dynamics of size and biomass of mature population of earthworms E. fetida

\section{Effects of the insecticide Actara 25WG in D. veneta earthworms}

Different response to the neonicotinoid insecticide was observed in $D$. veneta earthworms. The xenobiotic increased the size and biomass of mean populations of these worms, yet the effect was insignificant (size $\mathrm{t}=0.3207, \mathrm{p}>0.05$; biomass $\mathrm{t}=0.8562$, $\mathrm{p}>0.05$ ) (Fig. 4).

Actara $25 W G$ only produced change in the number of mature $D$. veneta specimens. More of these were found in the containers with the xeno- 


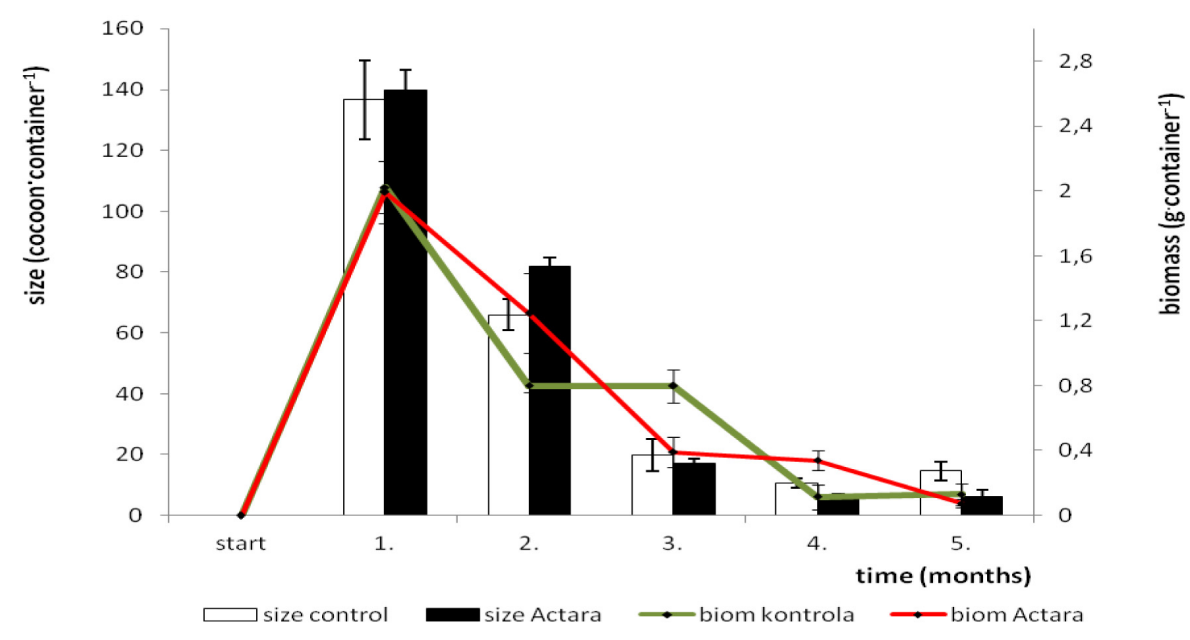

Figure 3. Effects of the xenobiotic Actara $25 W G$ in the dynamics of size and biomass of cocoon population of earthworm E. fetida

Table 2. Effects of xenobiotic Actara $25 W G$ in the number and biomass of immature earthworms E. Fetida

\begin{tabular}{|c|c|c|c|c|c|c|}
\hline \multicolumn{7}{|c|}{ Population size (specimen container $^{-1} \pm$ SD) } \\
\hline Time (months) & Start & $1 .{ }^{*}$ & $2 .^{*}$ & ${ }^{*}{ }^{*}$ & $4 .^{*}$ & $5 .{ }^{*}$ \\
\hline Control & - & $2.7 \pm 0.23$ & $10.0 \pm 2.7$ & $47.7 \pm 5,9$ & $21.3 \pm 5.1$ & $32.3 \pm 1.5$ \\
\hline Actara & - & $1.3 \pm 0.28$ & $9.3 \pm 1.5$ & $42.7 \pm 4.3$ & $15.0 \pm 1.7$ & $57.3 \pm 6.8$ \\
\hline \multicolumn{7}{|c|}{ Biomass $\left(\mathrm{g}^{*}\right.$ container $\left.{ }^{-1} \pm \mathrm{SD}\right)$} \\
\hline \multirow{2}{*}{ Control } & - & 0.3605 & 0.4083 & 10.4360 & 2.7060 & 6.6506 \\
& - & \pm 0.0661 & \pm 0.0107 & \pm 1.1741 & \pm 1.0900 & \pm 1.0431 \\
\hline \multirow{2}{*}{ Actara } & - & 0.0667 & 0.3900 & 5.2277 & 1.2463 & 6.3327 \\
& & \pm 0.0047 & \pm 0.0457 & \pm 0.2448 & \pm 0.2520 & \pm 0.4351 \\
\hline
\end{tabular}

*- at the end of the month

biotic $(\mathrm{t}=4.0256, \mathrm{p}<0.05)$. No effects of the formulation were identified in their biomass $(\mathrm{p}>0.05)$ (Fig. 5). The xenobiotic in question did not influence the population size $(\mathrm{p}>0.05)$ and biomass $(p>0.05)$ of immature specimens (Table 3 ) or their reproduction (number of cocoons) (Fig. 6).

The findings show greater differences in the responses of specific specimens of $D$. veneta earthworm compared to E. fetida earthworm. Coefficients of variation in the relevant characteristics are presented in the following table (Table 4).

\section{DISCUSSION}

Neonicotinoid insecticides have been in use since the 1990s (Feltham et al. 2014). Their growing usage is associated, among others, with the wide range of their applications (they can be used in the form of both granulates and concentrates) (Sánchez-Bayo \& Hyne 2014). The insecticides, however, present certain problems. These should be investigated not only because of the harmful impacts on honey bees (Sánchez-Bayo \& Hyne 2014); it is also important to gain insight into the effects of exposing other organisms to these substances. There is still scarcity of evidence related to the impact of neonicotinoids on the soil environment, and more specifically earthworms, which are important representatives of soil ecosystems. They account for over $70 \%$ of biomass in soil and have a significant role in the functioning of the ecosystem (Blouin et al. 2013). Some authors, e.g. Sánchez-Bayo \& Hyne (2014), argue that these insecticides constitute a real risk for earthworm populations, depending on the concentration of the medium and duration of exposure, as well as dosage and species-specific sensitivity.

Gomez-Eyles et al. (2009) demonstrated varied dose-dependent response of E. fetida earthworms to the neonicotinoid imidacloprid, in an artificial soil test. They tested 12 doses of this insecticide $(0.114 ; 0.182 ; 0.291 ; 0.466 ; 0.745$; $1.19 ; 1,91 ; 3.05 ; 4.88 ; 7.8 ; 12.5$ and $20.0 \mathrm{mg} \cdot \mathrm{kg}^{-1}$ ) over a period of 21 days, and showed that starting with the dose of $1.91 \mathrm{mg} \cdot \mathrm{kg}^{-1}$ the insecticide 


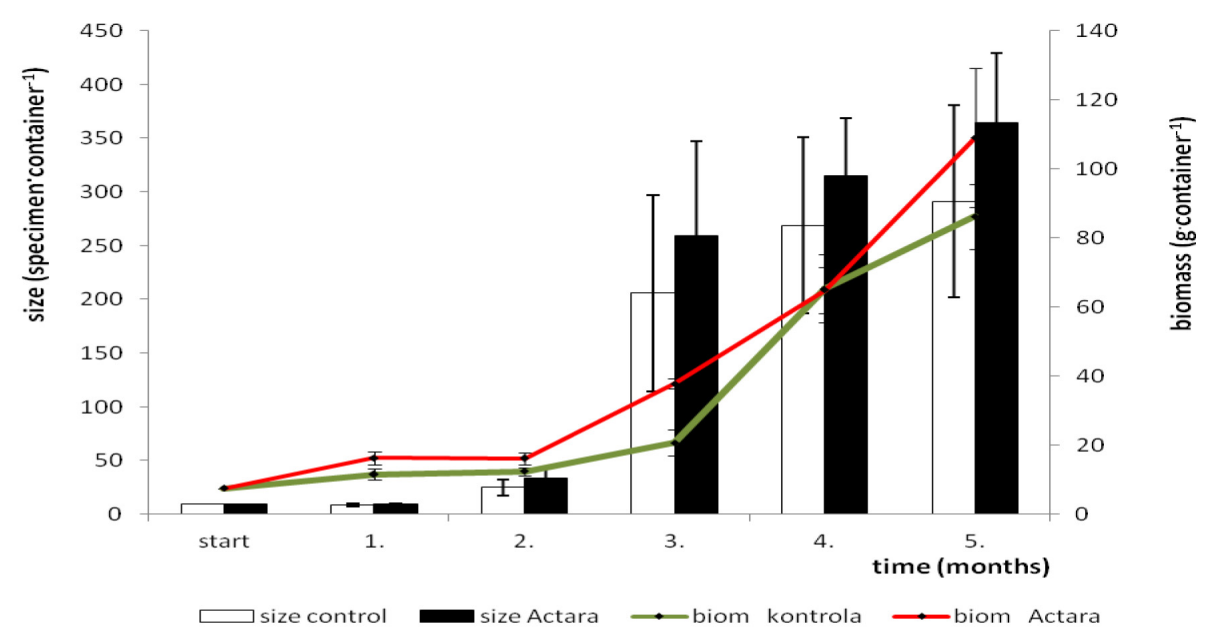

Figure 4. Effects of the xenobiotic Actara $25 W G$ in the dynamics of size and biomass of $D$. veneta earthworm population

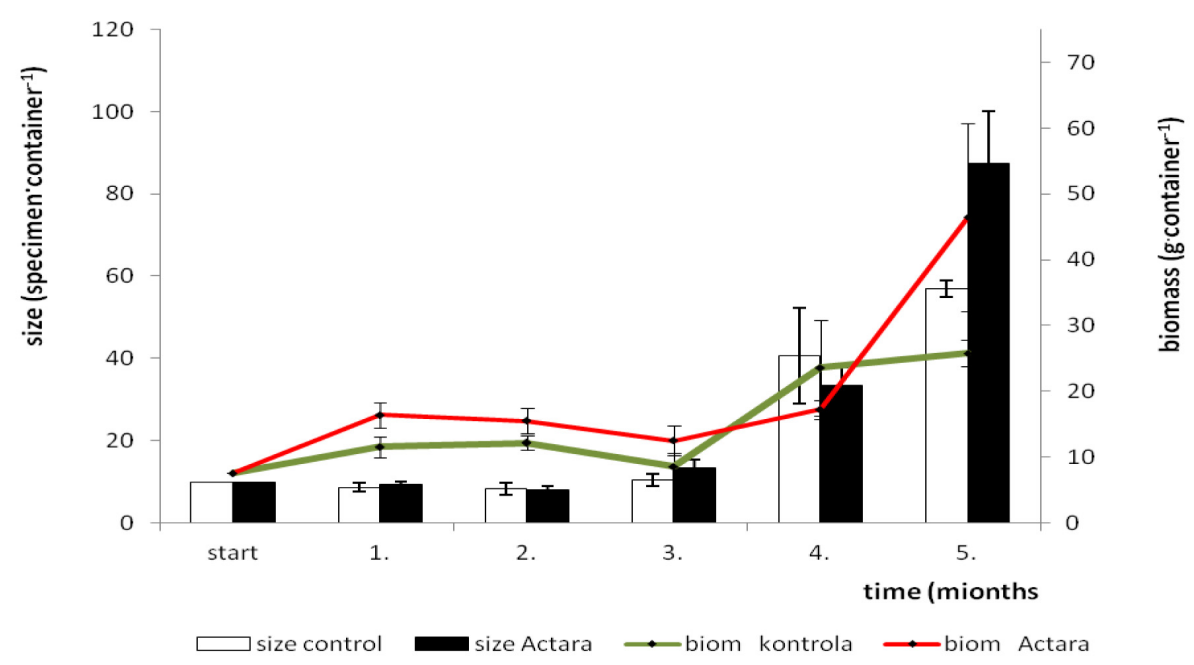

Figure 5. Effects of the xenobiotic Actara $25 W G$ in the dynamics of size and biomass of mature D. veneta earthworm population

Table 3. Effects of xenobiotic Actara $25 W G$ in the number and biomass of immature D. Veneta earthworms

\begin{tabular}{|c|c|c|c|c|c|c|}
\hline \multicolumn{7}{|c|}{ Population size (specimen'container ${ }^{-1} \pm \mathrm{SD}$ ) } \\
\hline Time (months) & Start & $1 .^{*}$ & $2 .{ }^{*}$ & $3 .{ }^{*}$ & $4{ }^{*}$ & $5 .{ }^{*}$ \\
\hline Control & - & - & $17.0 \pm 6.0$ & $195.3 \pm 91.5$ & $228.3 \pm 91.7$ & $234.3 \pm 91.7$ \\
\hline Actara & - & - & $26.0 \pm 9.5$ & $245.7 \pm 88.5$ & $281.3 \pm 54.3$ & $277.0 \pm 54.0$ \\
\hline \multicolumn{7}{|c|}{ Biomass (g*container ${ }^{-1} \pm$ SD) } \\
\hline Control & - & - & $0.3666 \pm 0.1296$ & $12.2064 \pm 2.1085$ & $41.8765 \pm 15.1546$ & $60.4352 \pm 10.1693$ \\
\hline Actara & - & - & $0.6666 \pm 0.3183$ & $25.3395 \pm 3.4138$ & $47.7068 \pm 6.0558$ & $62.6052 \pm 14.3086$ \\
\hline
\end{tabular}

*-at the end of the month

significantly reduced both the population size and biomass of E. fetida.

Furthermore, organisms are frequently affected by unexpected synergistic and antagonistic reactions of neonicotinoids and other xenobiotics occurring in soil (Laskowski \& Migula 2004). Numerous researchers investigate the effects produced by crop protection chemicals in earthworms, yet these studies mostly focus on the species of E. fetida (Pelosi et al. 2013; Zhang et al. 2014; Wang et al. 2015a, b).

It has been established that when exposed to chemical stressors, earthworm may modify their energy balance and (depending on physiological 


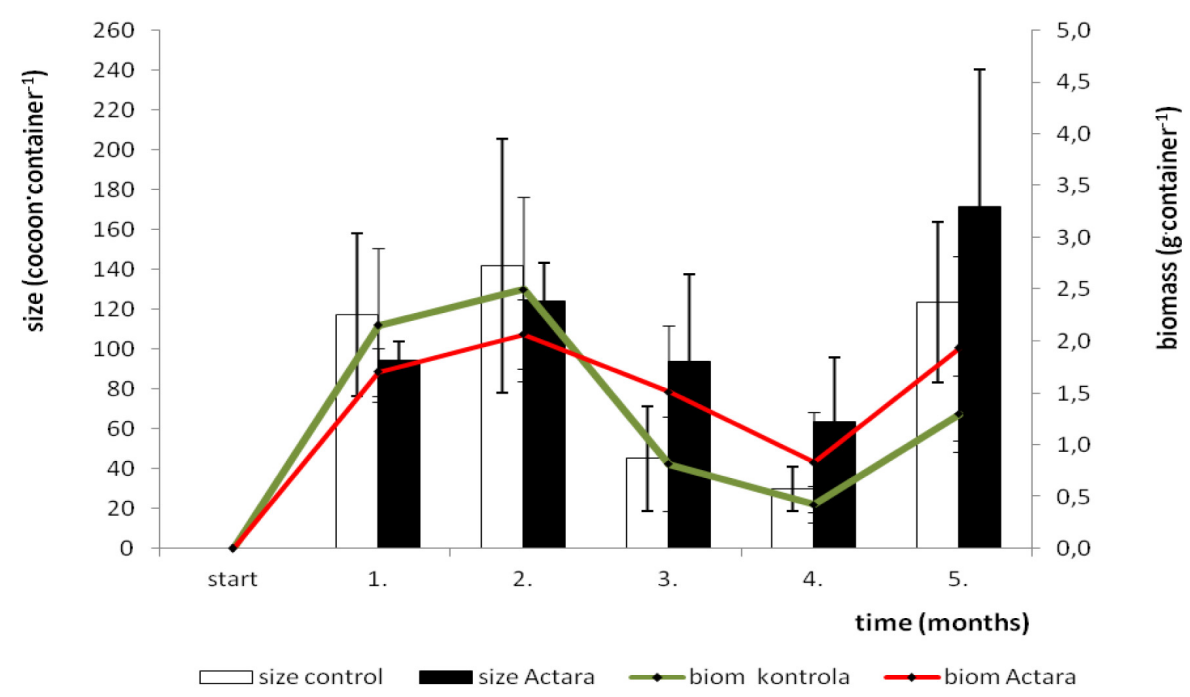

Figure 6. Effects of the xenobiotic Actara $25 W G$ in the dynamics of size and biomass of cocoon population of D. veneta earthworm

Table 4. Variation in responses of the species to the presence of the neonicotinoid Actara $25 \mathrm{WG}$

\begin{tabular}{|c|c|c|c|c|c|c|}
\hline \multirow[b]{2}{*}{ Species } & \multirow[b]{2}{*}{ Substrate } & \multirow[b]{2}{*}{ Characteristics } & \multicolumn{4}{|c|}{ Coefficient of variation (\%) } \\
\hline & & & $\begin{array}{c}\text { Whole } \\
\text { population }\end{array}$ & $\begin{array}{c}\text { Mature } \\
\text { specimens }\end{array}$ & $\begin{array}{l}\text { Immature } \\
\text { specimens }\end{array}$ & Cocoons \\
\hline \multirow{4}{*}{ E. fetida } & \multirow{2}{*}{ Control } & population size & 12 & 5 & 11 & 9 \\
\hline & & biomass & 5 & 5 & 11 & 3 \\
\hline & \multirow{2}{*}{ Actara } & population size & 10 & 4 & 11 & 6 \\
\hline & & biomass & 3 & 2 & 11 & 4 \\
\hline \multirow{4}{*}{ D. veneta } & \multirow{2}{*}{ Control } & population size & 33 & 16 & 37 & 33 \\
\hline & & biomass & 13 & 16 & 23 & 32 \\
\hline & \multirow{2}{*}{ Actara } & population size & 35 & 16 & 25 & 32 \\
\hline & & biomass & 13 & 19 & 18 & 32 \\
\hline
\end{tabular}

* low variation $(0-20 \%), * *$ moderate variation $(20-40 \%)$, *** high variation $(40-60 \%)$

(based on: Stanisz 2006)

condition) increase or decrease the energy expenditure required for detoxication. This should result in a greater chance of survival under hazardous conditions, at the same time leading to e.g. reduced production. Sometimes organisms allocate excess energy to the production of biomass or cocoons. They may also apply mixed strategies where, for instance increased energy expenditure is initially used for detoxication and then e.g. for the production of biomass (Walker et al. 2002; Laskowski \& Migula 2004; Aira et al. 2007; Johnston et al. 2014).

Since organisms have a specified amount of energy at their disposal, it is similar in a polluted and a so-called "pure" environment (Walker et al. 2002; Laskowski \& Migula 2004). The use of energy from food is shown in Figure 7. It can be seen that when stressed, a specimen has to choose where to invest energy. The choice is linked with expending energy to detoxication (which should result in a greater chance of survival, yet it also reduces production) or with allocation of excess energy to production (which leads to a decrease in the level of detoxication).

The present study was conducted over a period of five months. It was designed to identify lifehistory parameters in the populations of E. fetida and $D$. veneta earthworms in the presence of the xenobiotic Actara $25 W G$ applied once. It was found that the insecticide produced varied effects in the mean populations of these earthworm species. This may be linked with a number of factors, including, firstly, the sensitivity of the two species. The differences in their sensitivity would be confirmed by large disparity in the coefficients of variation in the characteristics under consideration. The response of earthworms may also depend on the decomposition time of the chemical 


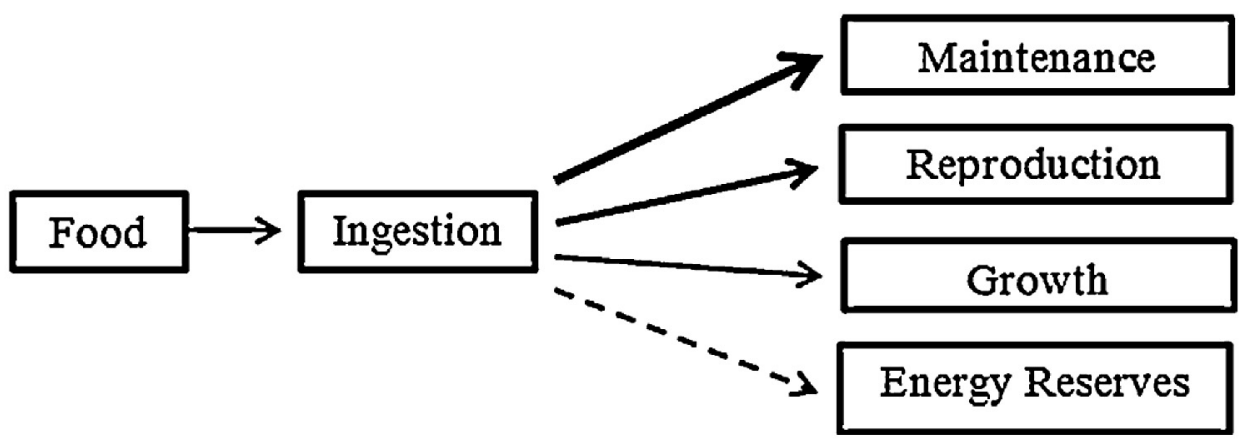

Figure 7. Model of standard use of energy obtained from food, based on a study of Eisenia fetida specimens (Johnston et al. 2014)

stressor, in particular if it was applied once. $A c$ tara $25 W G$ xenobiotic has low capacity for bioaccumulation and persistence in soil and water; its half-life in the aquatic and soil environments amounts to 11 and 51 days, respectively. Single short-term exposure to the so-called environmentally-safe dose produced positive effect in some of the characteristics in question. During the first two months after the agent was applied, E. fetida allocated energy to the production of cocoons. Starting from the third month, they reduced the reproduction and greater energy expenditures were designated for increase in the population size and biomass of mature specimens. Studies carried out by other authors (Helling et al. 2000 and Zhou et al. 2007) suggest that E. fetida earthworm exposed to chemical stress, e.g. in response to insecticide chlorpyrifos, are more likely to reduce reproduction than body growth.

During the initial stage of the experiment involving E. fetida, a positive effect was observed in their response to low dose of the xenobiotic. As it was mentioned before, this was related to an increased production of cocoons, size $(\mathrm{p}<0.05)$ and biomass $(p<0.001)$ not only in the entire population of earthworms but also to the population size $(p<0.05)$ and biomass $(p<0.001)$ of mature specimens, as well as population size of immature specimens $(\mathrm{p}<0.01)$. The application of the xenobiotic, however, affected the subsequent generation, as in the final stage of the experiment there was a decrease in the total number of cocoons produced by these earthworms $(\mathrm{p}<0.05)$.

As for $D$. veneta, the insecticide produced positive effects only in the mature specimens. At the end of the experiment, their number was significantly greater in the container with Actara $25 W G(\mathrm{p}<0.05)$.

This response, observed in both annelid species, may also be explained by the phenomenon of hormesis, or the fact that an organism's defence system works in such a way as to enable beneficial effects, in response to small doses (Laskowski \& Migula 2004). Furthermore, according to Calabrese (2005) the organisms exposed to low doses of chemicals frequently compensate for the negative impacts because such low doses may have stimulating effect, and at the next stage, the organism regains homeostasis. Alternatively, large doses frequently produce adverse effects, which are usually irreversible.

Alves et al. (2013) applied chronic toxicity tests to examine the influence of six insecticides (fipronil, imidacloprid, thiametoxam, captan, carboxin, and thiram) on Eisenia fetida andrei earthworms. Out of all these agents, only the neonicotinoid insecticide fipronil, applied at the lowest concentration (62.5 $\mathrm{mg} \cdot \mathrm{kg}^{-1}$ dry soil), produced a significant increase in the biomass of the exposed earthworms, compared with controls. Another neonicotinoid, i.e. imidacloprid, was found to significantly decrease the biomass. The remaining insecticides did not affect the red worms.

High acute toxicity of neonicotinoids (imidacloprid, clothianidin, nitenpyram, thiacloprid and acetamipryd) for mature E. fetida specimens was also reported by Wang et al. (2015a) who performed an experiment based on artificial soil test (OECD 1984). All the agents reduced the number and mass of cocoons, as well as the number of juveniles hatching from a single cocoon. The most toxic agent was clothianidin - even at the dose of $4.34 \mathrm{mg} \cdot \mathrm{kg}^{-1}$.

The negative effects of neonicotinoids were also confirmed by an earlier study conducted by Wang et al. (2012). Out of all the 24 xenobiotics, representing six classes of chemicals (acetamiprid, imidachlopryd, nitenpyram and thiacloprid, antibiotics, insect growth regulators IGR, pyrethroids, carbamates and organophosphates 
and others), their findings showed that neonicotinoids were most toxic for earthworms.

These facts support the claim that neonicotinoids should be applied extremely cautiously or indeed their use should be restricted.

\section{CONCLUSIONS}

1. The findings suggest different sensitivity of $E$. fetida and $D$. veneta to the neonicotinoid Actara $25 W G$ and provide evidence for varied life strategies in contact with stress caused by the agent.

2. During a short survivability test (period of 5 months, 155 days), the insecticide applied at the dose recommended as safe by the manufacturer, produced varied responses in the populations of the two species of earthworms: - in E. fetida, low doses of Actara $25 W G$ stimulated increase in the size $(\mathrm{p}<0.05)$ and biomass $(p<0.001)$ of the mean populations, number of mature specimens $(p<0.05)$ and their biomass $(p<0.001)$ as well as the number of immature specimens $(p<0.01)$. However, the application of Actara led to a reduced reproduction of $E$. fetida - there was a decrease in the number of cocoons produced $(\mathrm{p}<0.05),-$ in D. veneta, low dose of Actara $25 W G$ only stimulated the size of mature populations $(p<0.05)$. It did not affect the remaining characteristics ( $p>0.05)$.

3 . The research should be continued under varying conditions, because even though the findings suggest that partly successful life strategies are promoted, yet they also show reproductionrelated hazards for the investigated species of earthworms.

\section{Acknowledgement}

We would like to thank to dr. Kevin R. Butt (University of Central Lancashire, School of Forensic and Applied Sciences, England) for his help in writing in English.

\section{REFERENCES}

1. Aira M., Dominguez J., Monroy F., Velando A. 2007. Stress promotes changes in resource allocation to growth and reproduction in a simultaneous hermaphrodite with indeterminate growth. Biological Journal of the Linnean Society, 91(4), 593-600.
2. Alves P.R.L., Cardoso E.J.B.N., Martines A.M., Sousa J.P., Pasini A. 2013. Earthworm ecotoxicological assessments of pesticides used to treat seeds under tropical condition. Chemosphere, 90, 2674-2682.

3. Blouin M., Hodson M.E., Delgado E.A., Baker G., Brussard L., Butt K.R., Dai J., Dendooven L., Peres G., Tondoh J.E., Cluzeau D., Brun J.-J. 2013. A review of earthworm impact on soil function and ecosystem services. European Journal of Soil Science, 64, 161-182.

4. Calabrese E.J. 2005. Paradigm lost, paradigm found: there-emergence of hormesis as a fundamental dose response model in the toxicological science. Environmental Pollution, 138, 378-411.

5. Feltham H., Park K., Goulson D. 2014. Field realistic doses of pesticide imidacloprid reduce bumblebee pollen foraging efficiency. Ecotoxicology, 23(3), 317-323.

6. Garczyńska M., Kostecka J. 2011a. Wpływ insektycydu Nomolt 150SC stosowanego przeciwko muchówkom w skrzynkach ekologicznych na cechy dżdżownic Eisenia fetida (Sav.). Inżynieria Ekologiczna, 27, 13-18.

7. Garczyńska M., Kostecka J. 2011b. Influence of Dimilin 25 WP on characteristics of earthworm Eisenia fetida Sav., vermicomposting organic waste. Ecological Chemistry and Engineering, 18(11), 1557-1563.

8. Garczyńska M., Kostecka J. 2012. Ograniczanie larw muchówek podczas wermikompostowania domowych odpadów organicznych w skrzynkach ekologicznych. Roczniki Gleboznawcze. LXIII (1), 18-21.

9. Gill R.J., Ramos-Rodriguez O., Raine N.E. 2012. Combined pesticide exposure severely affects individual- and colony-level traits in bees. Nature, 491, 105-108.

10. Gomez-Eyles J.L., Svendsen C., Lister L., Martin H., Hodson M.E., Spurgeon D. 2009. Measuring and modelling mixture toxicity of imidacloprid and thiaclopridon Caenorhabditis elegans and Eisenia fetida. Ecotoxicology and Environmental Safety, 72, 71-79.

11. Hallman C.A., Foppen R.P.B., Turnhout V., Kroon H., Jongejans E. 2014. Declines in insectivorous birds are associated with high neonicotinoid concentrations. Nature, 511, 341-343.

12. Helling B., Reinecke S.A., Reinecke A.J. 2000. Effects on fungicide cooper oxychloride on the growth and reproduction of Eisenia fetida (Oligochaeta). Ecotoxicology and Environmental Safety, 46, 106-116.

13. Jeschke P., Nauen R., Schindler M., Elbert A. 2010. Overview of the status and global strategy for neonicotinoids. Journal of Agricultural and 
Food Chemistry, 59, 2897-2908.

14. Jeschke P., Nauen R., Beck M.E. 2013. Nicotinica cetylocholinereceptoragonists: a milestone for modern crop protection. Angewandte Chemie International Edition, 52(36), 9464-9485.

15. Johnston A.S.A., Hodson M.E., Thorbek P., Alvarez T., Sibly R.M. 2014. An energy budżet agentbased model of earthworm populations and its applications to study the effects of pesticides. Ecological Modeling, 280, 5-17.

16. Jovana M., Tanja M., Mirjana S. 2014. Effects of three pesticides on the earthworm Eisenia fetida (Savigny 1826) under laboratory conditions: Assessment of mortality, biomass and growth inhibition. European Journal of Soil Biology, 62, 127-131.

17. Komisja Europejska. 2013. Comission Implementing Regulation (EU) 485/2013. Amending of approval of the active substances clothianidin, thiamethoxam and imidacloprid and prohibiting the use and sale of seeds treated with plant protection containing those active substances.

18. Kostecka J. 2000. Investigation into vermicomposting of organic wastes. Scient. Pap. of Agr. Univ. of Cracow, 268, 1-88. (in Polish).

19. Kreutzweiser D.P., Thompson D.G., Scar T.A. 2009. Imidacloprid in leaves from systematically treated trees may inhibit litter breakdown by nontarget invertibrates. Ecotoxicology and Environmental Safety, 72(4), 1053-1057.

20. Krüpke C.H, Long E.Y. 2015. Intersections between neonicotinoid seed treatments and honey bees. Current Opinion in Insect Science, 120, 1-6.

21. Laskowski R., Migula P. 2004. Ecotoxicology. From the cell to the ecosystem (in Polish). PWRiL, Warszawa.

22. OECD. 1984. Test 207: Earthworm, Acute Toxicity Tests, OECD Guidelines for the Testing of Chemicals, Section 2, OECD Publishing, Paris. DOI: http://dx.doi.org/10.1787/9789264070042-en.

23. OECD. 2004. Test No. 222: Earthworm Reproduction Test (Eisenia fetida/Eisenia andrei), OECD Guidelines for the Testing of Chemicals, Section 2, OECD Publishing, Paris. DOI: http://dx.doi. org/10.1787/9789264070325-en

24. Pelosi C., Bertrand M., Capowiez Y., Boizard H., Roger-Estrade J. 2009. Earthworm collection from agricultural fields: Comparisons of selected expellants in presence/absence of hand-sorting. European Journal of Soil Biology, 45, 176-183.

25. Pelosi C., Barot S., Capowiez Y., Hedde M., Vandenbulckie F. 2013. Pesticides and earthworms. A review. Agronomy for Sustainable Development, 1-30.
26. Sánchez-Bayo F., Hyne R.V. 2014. Detection and analysis of neonicotinoids in river waters - Development of a passive sampler for three commonly used insecticides. Chemosphere, 99, 143-151.

27. Simon-Delso N., Amaral-Rogers V., Belzunces L.P., Bonmatin J.M., Chagnon M., Downs C., Furlan L., Gibbons D.W., Giorio C., Girolami V., Goulson D., Kreutzweiser D.P., Krupke C.H., Liess M., Long E., McField M., Mineau P., Mitchell E.A.D., Morrissey C.A., Noome D.A., Pisa L., Settele J., Stark J.D., Tapparo A., Van Dyck H., Van Praagh J., Van der Sluijs J.P., Whitehorn P.R., Wiemers M. 2015. Systemic insecticides (neonicotinoids and fipronil): trends, uses, mode of action and metabolites. Environmental Science and Pollution Research, 22, 5-34.

28. Stanisz A. 2006. An affordable statistic course using STATISTICA PL on examples of medicine (in Polish). StatSoft Polska Sp. z o.o. Kraków, pp. 532.

29. Uhl P., Bucher R., Schafer R.S., Entling M.H. 2015. Sublethal effects of imidacloprid on interactions in a tritrophic system on non target species. Chemosphere, 132, 152-158.

30. Walker C.H., Hopkin S.P., Sibly R.M., Peakall D.B. 2012. Principles of Ecotoxicology, Fourth Edition. CRC Press, pp. 386.

31. Wang Y., Cang T., Zhao X., Yu R., Chen L., Wu C., Wang Q. 2012. Comparative acute toxicity of twenty-four insecticides to earthworm Eisenia fetida. Ecotoxicology and Enviromental Safety, 79, 122-128.

32. Wang K., Pang S., Mu X., Qi S., Li D., Cui Fe., Wang Ch. 2015a. Biological responses of earthworm, Eisenia fetida, to five neonicotinoid insecticides. Chemosphere, 132, 120-126.

33. Wang K., Mu X., Qi S., Chai T., Pang S., Yang Y., Wang C, Jiang J. 2015b. Toxicity of a neonicotynoid insectidcide, guadipyr in (Eisenia fetida). Ecotoxicology and Environmental Safety, 114, 17-22.

34. Whitehorn P.R., O'Connor S., Wackers F.L., Goulson D. 2012. Neonicotinoid pesticide reduces bumble bee colony growth and queen production. Science, 336, 351-352.

35. Zhang Q., Zang B., Wang C. 2014. Ecotoxicological effects on the earthworm Eisenia fetida following exposure to soil contaminated with imidacloprid. Environmental Science and pollution Research International, 21(21), 12345-53.

36. Zhou S.P., Duan C.Q., Fu H., Chen Y.H., Wang X.H., Yu Z.F. 2007. Toxicity assessment for chlorpyrifos-contaminated soil with three different earthworm test methods. Journal of Environmental Sciences, 19, 854-858. 